\title{
A Rapid Review of Barriers to Volunteering for Potentially Disadvantaged Groups and Implications for Health Inequalities
}

\author{
Kris Southby $^{1}$ (D) Jane South ${ }^{1} \cdot$ Anne-Marie Bagnall ${ }^{1}$
}

Published online: 23 September 2019

(C) The Author(s) 2019

\begin{abstract}
Despite volunteering being a feature of community life in the UK, differences as to who volunteers are evident. Reporting on a rapid review of the evidence on volunteering and inequalities, the aim of this paper is to provide an overview of the breadth and interconnectedness of barriers to volunteering for potentially disadvantaged groups. Sixty-seven articles were identified, to produce a map of factors affecting volunteer participation. Findings suggest that whilst different demographic groups experience specific barriers to volunteering, there are areas of commonality. Analysis shifts the onus of volunteering away from the level of individual choice (a dominant emphasis in policy and practical discussions around promoting volunteering) and towards the influence of structural factors related to broader exclusionary processes. Those who potentially have the most to gain from volunteering are the least likely to participate. Whilst the benefits of volunteering are increasingly documented by research and championed by policy, there are questions about the success of this approach given that the underlying social inequalities present substantive barriers to volunteering and must be addressed to promote greater access.
\end{abstract}

Keywords Volunteering - Inequalities · Barriers - Social capital

Electronic supplementary material The online version of this article (https://doi.org/10.1007/s11266-019-00119-2) contains supplementary material, which is available to authorized users.

Kris Southby

k.southby@leedsbeckett.ac.uk

1 Centre for Health Promotion Research, Leeds Beckett University, PD519, City Campus, Leeds LS1 8HE, UK

\section{Introduction}

The beneficial health and well-being outcomes of volunteering are well documented. Among other things, volunteering can improve the physical and mental health of volunteers (Alspach 2014; Fegan and Cook 2014; Salt et al. 2017; Yeung et al. 2017), provide a positive pathway for those experiencing social isolation (O'Brien et al. 2010; South et al. 2013), reduce hospital service usage (Kim and Konrath 2016), and help connect services to at-risk groups (Gilbert et al. 2018; Harris et al. 2015). The intrinsic value of volunteering and the societal benefits that result from increased volunteerism are increasingly recognised by policy makers (O'Donnell et al. 2014). In the United Kingdom (UK), for example, volunteering is framed as an integral part of the health and care system (Department of Health 2011; Naylor et al. 2013) and an activity that should be promoted to support greater self-care and prevention efforts in communities (NHS England 2014; People and Communities Board 2016). Whilst there is wide endorsement of the benefits of volunteering for volunteers and recipients of volunteering, and to communities and society more generally, any concerns around potential inequalities in volunteering do not feature strongly in what is a broadly positive discourse. However, there are marked variations in volunteering prevalence both between and within countries and emergent patterns as to who is most likely to volunteer. There is a tenfold variation in volunteering rates across Europe (Hupert et al. 2009). In England, 27\% of the adult population take part in formal volunteering 'regularly' (once a month) and $42 \%$ do so 'occasionally' (less than once a month but more than once a year) (Cabinet Office 2016). The variations in prevalence and therefore the unequal distribution of health and well-being benefits from volunteering suggest that this may be a health inequalities 
issue. The aim of the paper is to provide an overview of both the breadth and interconnectedness of what helps or hinders volunteering for a selection of social demographic groups at risks of experiencing disadvantage. It extends and updates existing empirical and theoretical insights on this topic by adopting a health equity lens to suggest that underlying social inequalities present substantive barriers to volunteering that must be addressed to promote greater access. This paper explores barriers to volunteering that exist at structural and institutional as well as personal levels. We understand 'barriers' to mean any factor or combination of factors that constrains engagement in volunteering whether at structural, institutional, or personal levels. The paper shifts the focus away from the level of individual choice and towards the influence of broader patterns of social exclusion and economic inequality as major determinants of volunteerism.

Volunteering is not an irrational act, and inquiry into the philosophical, sociological, and psychological bases for decisions to undertake such work is needed (Musick and Wilson 2007). Work commitments are the most frequently cited reason for not volunteering in England (The National Archives 2016). Other reasons include childcare commitments and looking after the home, doing other things, not knowing about volunteering opportunities, study commitments, looking after an elderly relative, disability, and age. Volunteer prevalence is not just an individual choice-to volunteer or not-but is also affected by what other people are thinking and doing (Wilson and Music 1997). Like paid work, a 'market' exists for volunteer labour in which admittance is conditional on one's qualifications (Wilson and Music 1997). Wilson (2012) supposes that volunteerism is based on a combination of one's subjective dispositions (i.e. individual personality traits, motives, attitudes, norms, and values), personal resources, life course experiences, and social context. Similarly, Wilson and Musick (1997) suggest that entry into the volunteer labour force requires three different kinds of resources: human, social, and cultural capital. Clearly, a complex interaction of variables influences why volunteers do what they do and why others decline to volunteer. This paper explores this mix of variables for specific demographic groups by using a structural determinants framework which demonstrates how barriers and facilitating factors exist through individual, interpersonal/familial, work environment/institutional and broader socio-economic and political levels.

\section{Methods}

In November 2015, Volunteering Matters, a UK charity concerned with supporting and promoting inclusive volunteering, instigated a collaborative project to embed more fully into the health system an understanding of volunteering as an effective public health intervention and a means of addressing social exclusion and health inequalities. A key objective was to identify actions to enable those less able to volunteer to overcome barriers and gain the health and well-being benefits of volunteering. A rapid evidence review was commissioned to inform development of proposals for policy and practice.

Our review methodology maps to the eight steps of a Knowledge to Action 'evidence summary' described by Khangura et al. (2012) (see Table 1). This approach was appropriate due the requirement for a summary of existing knowledge and scoping of key barriers to inform later policy advocacy. Whilst 'systematic reviews' are often considered the preeminent mode of comprehensively synthesising evidence, this may not always be the case, particularly where clarification and insight is needed over identifying that which is common in the findings (Greenhalgh et al. 2018). Evidence summaries-and the overall class of 'rapid reviews' into which they fall-are a streamlined approach to synthesising available evidence within a short time frame to serve as an information brief for discussion on policy issues and support the direction and evidence base for policy initiatives (Khangura et al. 2012; Thomas et al. 2013; Varker et al. 2015). Provided the limitations are sufficiently understood and procedures transparent, the overview provided through rapid review may be considered reasonable and appropriate in the context of informing policy and decision makers concerned with efficacy or effectiveness (Khangura et al. 2012; Varker et al. 2015).

\section{Steps 1-3: Developing the Review}

The review was undertaken between in January 2016 and May 2017 by two researchers from the Centre of Health Promotion Research (KS, JS), with consultative support provided by another (AMB). The research team, alongside representatives from Volunteering Matters and The King's Fund, formed the project steering group. Decisions about the review (i.e. specific research question, initial findings, and analysis) were discussed with the steering group throughout the review process.

The aim of the review developed iteratively. Following initial steering group discussion, broad questions concerning the outcomes of, and processes involved in, volunteering were identified (i.e. "what is the relationship between volunteering and health inequalities?', 'how can statutory and non-statutory services engage with marginalised groups/individuals as volunteers?'). Through further discussion and preliminary literature searches, it was decided to narrow the focus of the review to inequalities within volunteering and to the specific research question. 
Table 1 Outline of our rapid review procedure mapped to knowledge to action evidence summary

\begin{tabular}{|c|c|c|}
\hline $\begin{array}{l}\text { Knowledge to } \\
\text { action step }\end{array}$ & Task & What we did \\
\hline Step 1 & Needs assessment & Developing the review: \\
\hline Step 2 & Question development and refinement & Stakeholder meetings to agree review question(s) \\
\hline Step 3 & Proposal development and approval & \\
\hline Step 4 & Systematic literature search & $\begin{array}{l}\text { Systematic literature search: systematic search of academic databases and } \\
\text { call for 'grey' literature }\end{array}$ \\
\hline Step 5 & Screening and selection of studies & $\begin{array}{l}\text { Screening and study selection: title and abstracts read, relevant papers read } \\
\text { in full and onward citation searches conducted }\end{array}$ \\
\hline Step 6 & $\begin{array}{l}\text { Narrative synthesis of included studies } \\
\text { (including assignment of evidence level) }\end{array}$ & $\begin{array}{l}\text { Narrative synthesis: } \\
\text { Findings synthesised in relation to demographic descriptors. Six themes } \\
\text { and an overarching conceptual theme emerged }\end{array}$ \\
\hline Step 7 & Report production & $\begin{array}{l}\text { Report production: } \\
\text { Production of full and summary report or review, in conjunction with } \\
\text { steering group }\end{array}$ \\
\hline Step 8 & $\begin{array}{l}\text { Ongoing follow-up and dialogue with knowledge } \\
\text { users }\end{array}$ & $\begin{array}{l}\text { Ongoing follow-up: } \\
\text { Presentation of results to practice, production of a briefing paper based on } \\
\text { results }\end{array}$ \\
\hline
\end{tabular}

Table 2 Adapted protected characteristics (Equality Act 2010) framework

\begin{tabular}{ll}
\hline Protected characteristic under the Equality Act 2010 & Demographic descriptor used \\
\hline Age & Age \\
Disability & Disability \\
Gender reassignment & Gender \\
Sex & \\
Marriage and civil partnership & Relationship status \\
Pregnancy and maternity & Pregnancy/maternity \\
Race & Ethnicity \\
Religion or belief & Religion \\
Sexual orientation & Sexual orientation \\
& Social exclusion (including social capital, human capital, economic capital) \\
\hline
\end{tabular}

Moving beyond descriptions of volunteer prevalence, the review focused on inequalities across various socio-economic domains.

To explore barriers across a range of population groups where there is potential for disadvantage, we used the nine characteristics protected by the UK Equality Act 2010 (i.e. age, disability, gender reassignment, marriage and civil partnership, pregnancy and maternity, race, religion or belief, sex, sexual orientation) as an initial framework to map literature.

The specific research question guiding the review was: What helps and hinders people-especially those at risk of social exclusion-from taking part in volunteering? Barriers were identified as any factor or combination of factors that constrained engagement in volunteering whether at structural, institutional or personal levels (Harden et al. 2015).

\section{Step 4: Systematic Literature Search}

A systematic search of published and 'grey' literature concerning what helps and hinders people to volunteer was undertaken. To ensure the enquiry was broad and encompassed the multitude of exclusionary forces acting on potential volunteers, we adapted the characteristics protected under the UK's Equality Act 2010 into a framework to guide our search terms and results synthesis (see Table 2). We also included an additional 'social exclusion' descriptor to capture any crosscutting issues relating to socio-economic disadvantage. 
The literature search was conducted in March 2016 using Leeds Beckett University Library's 'Discover' portal, which searched over 120 academic databases, including health specific databases (i.e. MEDLINE, PsycINFO, ScienceDirect, SPORTDiscus). A set of search terms relating to the concept of 'volunteering' was combined with one or more sets of 'demographic descriptor' search terms (see supplementary material for full search strategy). Results were limited to English language publications and academic journals. No date or geographical restriction was applied. Research from a non-UK context was included as the review intended to identify broad potential barriers to volunteering rather than specific barriers experienced by those in the UK.

To identify relevant unpublished 'grey' literature, in January 2016 Volunteering Matters issued a call for evidence via the Network of National Volunteer-Involving Agencies (NNVIA) network. Members were asked to forward to the research team reports or evidence concerning barriers to volunteering, particularly for groups thought to be marginalised from volunteering.

\section{Step 5: Screening and Study Selection}

In total, sixty-seven records were included in the review (see Fig. 1). The search yielded 6094 items, consisting of 6082 published articles and twelve grey literature items. All titles and abstracts were initially screened for relevance by one member of the research team. Full papers were obtained and subjected to further screening if they reported an empirical study, systematic review, or relevant discussion paper about: (1) actual or perceived barriers to volunteering; (2) inequalities in volunteering rates; or (3) psychological factors (i.e. motivations) preventing or discouraging volunteering in relation to one or more demographic descriptors.

\section{Step 6: Narrative Synthesis}

Data were extracted by one reviewer (KS) from each included article concerning research methodology (including research methods and sample data), country in which the research was conducted, demographic descriptor(s) under exploration, and identified barriers to volunteering.

The extracted data from across the sixty-seven included records were synthesised narratively (Popay 2006). The identified barriers to volunteering were described in relation to each demographic descriptor. Six themes were then drawn out: socialisation, institutional factors, personal resources, view of volunteering, caring responsibilities, and employment. A seventh theme around social exclusion was also drawn out as a crosscutting, overarching concept. This narrative approach served to deepen understanding of the pertinent issues rather than just provide a summation of what is known (Greenhalgh et al. 2018).

\section{Steps 7-8: Dissemination and Follow-up}

In the first instance, the findings of the review were written up by the research team as a report for Volunteering Matters (Southby and South 2016b), with an accompanying summary report (Southby and South 2016a). The report went through a number of iterations following feedback from stakeholders.

The findings of the review were presented at a series of events in England (Coventry, York, Sheffield, Manchester) in the summer of 2017 where stakeholders from both
Fig. 1 Flowchart of literature search and screening results

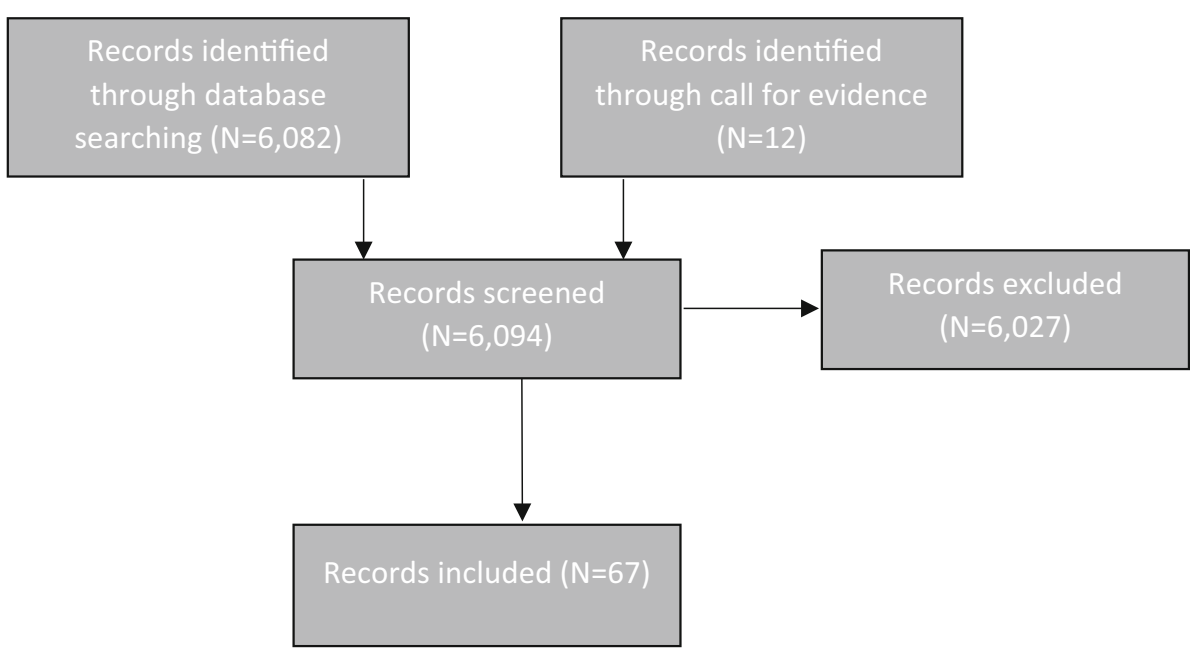


statutory and third-sector organisations had opportunities to comment on the relevance and significance of the review. Volunteering Matters produced a briefing based on the findings of the review to start to raise the issues on the policy agenda and to stimulate debate about what practical actions could be done to address volunteering inequalities at a local, regional, and national level.

\section{Findings}

Table 3 shows that the included studies were almost all from high-income countries. The evidence is dominated by studies from the USA $(n=27)$ and the UK $(N=15)$.

The content of the papers was diverse with some discussing issues for multiple demographic groups. The greatest number of articles discussed 'social inequalities' and volunteering $(n=34)$, followed by 'age' $(n=27)$, 'religion' ( $n=15)$, 'ethnicity' $(n=15)$, 'gender' $(n=15)$, and then 'disability' $(n=7)$ and 'relationship status' $(n=3)$. No literature was identified in relation to 'sexual orientation' or 'pregnancy/maternity' and volunteering, although three papers discussed having children in the household and volunteering. This may reflect a dearth of evidence in these areas rather than a lack of barriers to volunteering for these groups. The largest number of papers $(n=33)$ carried out secondary analysis of existing quantitative survey data. Eleven papers utilised a review methodology, ranging from narrative reviews to metaanalysis. Twenty-three papers collected empirical data, including quantitative data $(n=9)$, qualitative data $(n=7)$,

Table 3 Geographical focus of included studies

\begin{tabular}{lc}
\hline Country & Number \\
\hline United States of America & 27 \\
United Kingdom & 15 \\
Australia & 5 \\
Canada & 2 \\
Netherlands & 3 \\
Spain & 2 \\
Republic of Ireland & 2 \\
China & 1 \\
Israel & 1 \\
Norway & 1 \\
Germany & 1 \\
France & 1 \\
Italy & 1 \\
Mexico & 1 \\
Europe & 2 \\
International & 2 \\
Unspecified/Unclear & 2 \\
\hline
\end{tabular}

and mixed methods $(n=7)$. Mapping the methodologies used to explore barriers to volunteering for different demographic groups (see Table 4) illustrates the reliance to date on survey methodologies and a relative dearth of qualitative and mixed-methods empirical evidence. Contrary to this general pattern is the experience of people with disabilities (broadly defined) who have been the subject of relatively more qualitative and mixed-methods research and little survey analysis.

The identified papers described a range of barriers affecting volunteering for different demographic groups. Table 5 maps the identified barriers to volunteering to the different demographic groups. It demonstrates the breadth of potential issues for different groups but not the volume or quality of identified evidence. Some groups, such as 'age', 'disability', and 'gender', appear to experience a broader range of barriers to volunteering.

Among older people, poor health and physical functioning, poverty, stigma, lack of skills, poor transport, time constraints, inadequate volunteer management, and other caring responsibilities are highlighted in the identified literature as potential barriers to volunteering. For younger people, a lack of institutional support and not being socialised into volunteering roles are barriers identified in the literature. The literature also indicates that younger people may have negative perceptions of volunteering, as well as not having time to volunteer. A significant barrier to volunteering for people with a disability can be the disablist attitudes of others, including a stigma associated with impairment and perceptions that people with a disability have very little to offer or that supporting someone with a disability to volunteer will be too resource intensive. Some people with a disability may themselves express concerns about participating outside of 'safe' spaces and may sometimes require additional skills development to take part in volunteering. Men and women may have different motivations for volunteering and all identified barriers to volunteering appear to have a gender element. The identified papers suggest women are required to devote a greater proportion of their 'free time' in order to volunteer than men. Women are constrained to a greater extent than men by housework and additional caring responsibilities (for children and elderly relatives) and are likely to receive less support from employers. No research on volunteering and pregnancy/maternity (or paternity) was found in this review, although having (school aged) children in the household was found to be positively associated with both formal and informal volunteering in three identified papers and in survey data. Raising children may make parents more aware of volunteering opportunities (i.e. through schools and youth groups/activities) and may create a societal expectation to socialise children into socially responsible roles. The papers suggest that different cultures 
Table 4 Matrix of demographic descriptor and methodology for included papers

\begin{tabular}{|c|c|c|c|c|c|}
\hline & $\begin{array}{l}\text { Review } \\
\text { method }\end{array}$ & $\begin{array}{l}\text { Secondary survey } \\
\text { analysis }\end{array}$ & $\begin{array}{l}\text { Qualitative } \\
\text { (empirical) }\end{array}$ & $\begin{array}{l}\text { Quantitative } \\
\text { (empirical) }\end{array}$ & $\begin{array}{l}\text { Mixed methods } \\
\text { (empirical) }\end{array}$ \\
\hline Age & 5 & 8 & 1 & 6 & 7 \\
\hline Disability & 3 & & 2 & & 2 \\
\hline Gender & & 10 & 1 & 2 & 2 \\
\hline Relationship status & & 3 & & & \\
\hline \multicolumn{6}{|l|}{ Pregnancy/maternity } \\
\hline Ethnicity & 2 & 9 & & 2 & 2 \\
\hline Religion & 2 & 12 & 1 & & \\
\hline \multicolumn{6}{|l|}{ Sexual orientation } \\
\hline Social inequalities & 7 & 20 & 2 & 2 & 3 \\
\hline Mixed & & & 1 & & \\
\hline
\end{tabular}

may think about and value volunteering differently. People from minority ethnic groups may also experience limited access to volunteering infrastructures, feel alienated or excluded within volunteer organisations and environments, have fewer skills and resources to volunteer, and experience fewer positive outcomes from volunteering. The papers discussing volunteering and relationship (marital) status generally suggest a positive relationship between marriage and volunteering. However, a changing backdrop of family structures may be affecting the relationship between marriage and volunteering, particularly for women in terms of paid employment, having fewer children and having additional family care responsibilities. The identified literature focuses on heterosexual marriage, and no literature was identified specifically in relation to same-sex marriage or civil partnership. Church (or equivalent) attendance, in particular, is an influential factor in volunteering, possibly creating larger social networks and more opportunities to engage in volunteering, although the relationship to volunteering varies between religious affiliations. Some of the identified research warns that religion may form exclusionary boundaries around who can volunteer and what kind of activities are undertaken. Factors related to broader exclusionary processes and social, human, cultural, and economic capital have been identified in the research literature as key to participation in volunteering. The literature suggests that whilst volunteering is a mechanism for individuals to boost their personal, social, financial, and cultural resources in order to overcome exclusion, volunteering also consumes one's resources. This means that those with less personal and social resources are less able to volunteer and gain the associated benefits.

Whilst different demographic groups may experience unique barriers to volunteering, the review highlighted areas of commonality. For example, both older people
(Hussein and Manthorpe 2014) and those with disabilities (Farrell and Bryant 2009; Fegan and Cook 2012; Roker et al. 1998; Trembath et al. 2010) experienced their volunteering being limited to specific roles and/or organisations. Moreover, barriers to volunteering associated with specific demographic groups were compounded (and/or mitigated) by multiple socio-economic factors. For example, the barriers to volunteering experienced by different age groups were found to be affected by the gender, ethnicity, disability, socio-economic status, family background, and education of potential volunteers (Cramm and Nieboer 2015; Kay and Bradbury 2009; Mainar et al. 2015; McNamara and Gonzales 2011; Nicol 2012; Pantea 2013). A narrative account is now given of the main crosscutting factors affecting volunteering identified through the review.

\section{Socialisation}

The influence of socialisation on volunteering is most notably documented with regard to young people. Norms and values gained from friends and family help to explain why some people volunteer and others do not (Davis Smith 1999; Ishizawa 2015). Parents and friends who do not volunteer (Mainar et al. 2015; van Goethem et al. 2014), do not hold strong social justice values (Webber 2011), or do not see volunteering as part as their identity (Marta and Pozzi 2008) are likely to dissuade youth volunteering. Individuals are also influenced by their social environments across the life course, including norms, values, customs, and habits, which all affect volunteering behaviour (Davis Smith 1999; Ishizawa 2015; McNamara and Gonzales 2011; Youssim et al. 2015). For example, being religious may encourage volunteering through the teaching of obligation (Son and Wilson 2012), whilst the process of 


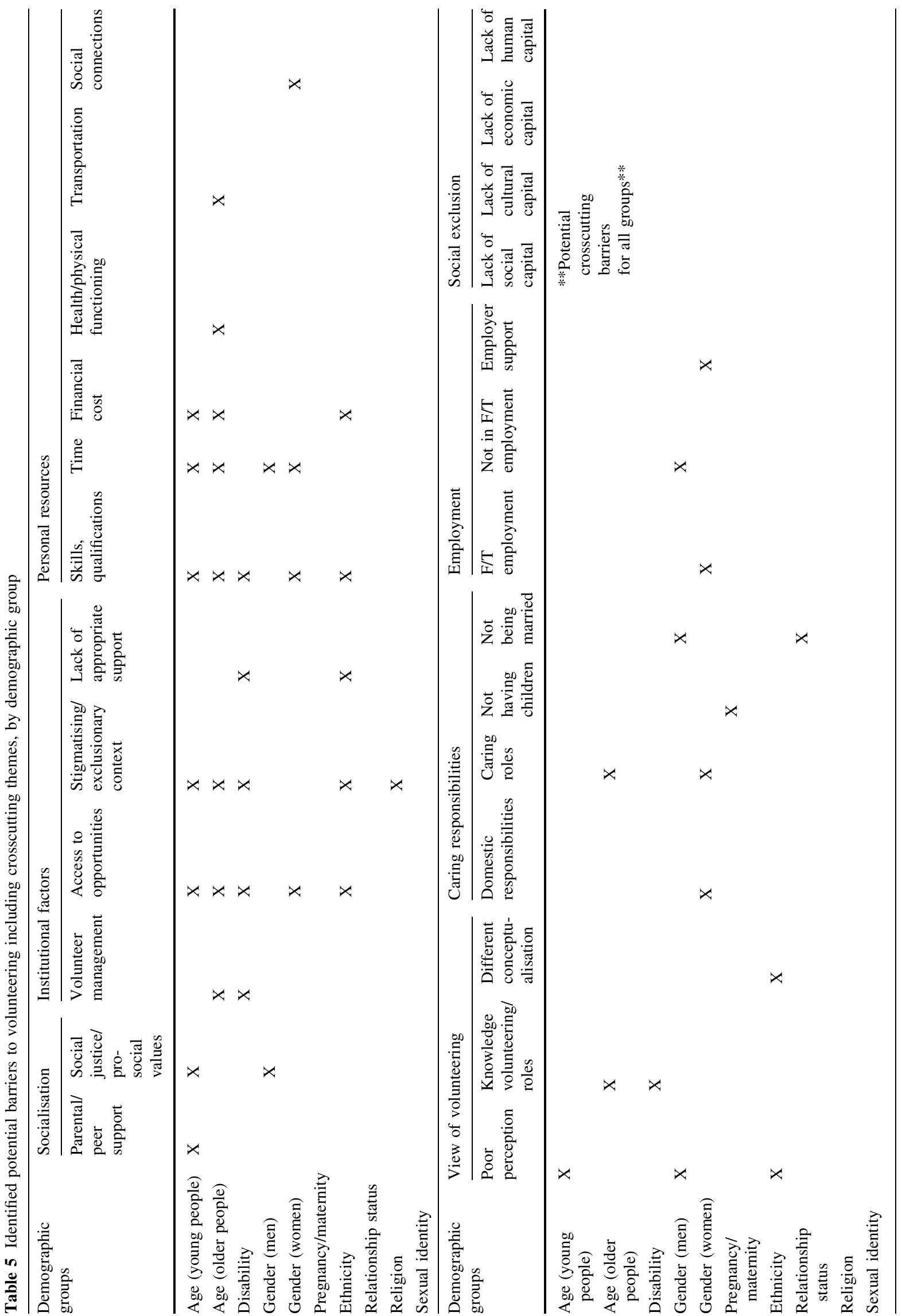


teaching children socially responsible roles may encourage parents to volunteer (Taniguchi 2006).

\section{Institutional Factors}

The volunteering of different demographic groups also appears to be affected, to varying degrees, by the organisation and conduct of volunteer-involving organisations. Poor volunteer management has been found to be a barrier to volunteering for older people (Fengyan et al. 2009) and men (Kolnick and Mulder 2007). Access to volunteering opportunities can be a barrier to volunteering. Clear entry points into volunteering and institutional support (i.e. school, church, community groups) are key facilitators for young people to volunteer (Webber 2011). Similarly, those from minority ethnic groups may have limited access to formal volunteer infrastructures (Rotolo and Wilson 2014). Volunteering might also be organised to take place in unfamiliar, alienating, or non-inclusive environments. Older people (Connolly and O'shea 2015; Suanet et al. 2009), people with physical and/or intellectual impairments (Farrell and Bryant 2009; Fegan and Cook 2012; Roker et al. 1998), young people (Davis Smith 1999), and people from minority ethnic groups (Bortree and Waters 2014; Ockenden 2007) have all reported not feeling welcome as volunteers within volunteer-involving organisations. Within voluntary roles, individuals may not receive appropriate support, discouraging them from volunteering further. Commitment to volunteers with a disability may be viewed as additional work (Roker et al. 1998) and therefore a low service priority for organisations with limited time and resources (Young and Passmore 2007). The availability of institutional support helps to explain why some young people volunteer and others do not (Davis Smith 1999; Ishizawa 2015).

The church (or other religious equivalent), for example, is an often discussed institution in the volunteering literature. Church attendance has been found to be an influential factor in volunteering (Layton and Moreno 2014; Storm 2015), creating larger social networks, and more opportunities for interaction and the acquisition of social and administrative skills involved in civic engagement/volunteering. However, the relationship is contingent on other factors, including religion and denomination. In the United States of America (USA), for example, volunteering has been found to be more strongly tied to attendance at black and evangelical churches compared to those who attend Catholic and mainline protestant churches (Johnston 2013; Wilson and Janoski 1995). Within African-American communities in the USA, the church may have a more mobilising effect for volunteering than in 'white' communities (Musick et al. 2000). In the UK, some researches have found that religious 'pluralists' - those who believe religions other than their own contain some basic truthsare more likely to volunteer than any other groups of religious people (Birdwell and Littler 2012). Moreover, whilst facilitating access to voluntary opportunities for some, the church can also form exclusionary boundaries around voluntary activity (Pathak and McGhee 2015).

\section{Personal Resources}

Individuals' personal resources have been found to be a barrier and/or an enabling factor towards volunteering. Participating in volunteering requires an individual investment of time, money, effort, and skill (i.e. for travel, expenses). Lack of time, for various reasons, has been found to be a barrier to volunteering for young people (Davis Smith 1999; Mainar et al. 2015; Nicol 2012) and both men and women; women may devote a greater proportion of their 'free time' to volunteering (Taniguchi 2006; Windebank 2008). Lack of financial resources to cover the costs associated with volunteering has been found to be a barrier for older people (Cattan et al. 2011; Fengyan et al. 2009), young people (Davis Smith 1999; Mainar et al. 2015; Nicol 2012), and people from minority ethnic groups (Mesch et al. 2006; Musick et al. 2000). Some people may not be able to take part in volunteering due to ill health. This has been found to be the case among older people, where poor health and physical functioning negatively correlates with volunteering (Cramm and Nieboer 2015; Lum and Lightfoot 2005). Older people (Fengyan et al. 2009), young people (Bang 2015; Davis Smith 1999), people with physical and/or intellectual impairments (Young and Passmore 2007), women (Bryant et al. 2003; Einolf 2011), and people from minority ethnic groups (Mesch et al. 2006; Musick et al. 2000) all face barriers to volunteering when they are perceived as lacking the desired skills for volunteer roles.

\section{Understanding of Volunteering}

The identified papers indicate that different demographic groups may think about and conceptualise volunteering differently, affecting their propensity to volunteer. Older people may lack knowledge around volunteer opportunities and roles (Fengyan et al. 2009). Other groups, including young people (Davis Smith 1999) and people with physical and/or intellectual impairments (Balandin et al. 2006), may hold negative views about volunteering. People from different ethnic and cultural backgrounds may also view volunteering differently. For example, African-American populations are less likely to see 'charity' as the best way 
to address social problems (Musick et al. 2000). In Chinese and Japanese cultures, older people may be less inclined to volunteer because of the implication that they are not being appropriately cared for by their family (Fengyan et al. 2009; Warburton and Winterton 2010).

\section{Caring Responsibilities}

Family structures and the way caring (and domestic) responsibilities are divided within households have been shown to impact volunteering. In general, marriage (McNamara and Gonzales 2011; Plagnol and Huppert 2010; Taniguchi 2006) and the presence of children (Einolf 2011; McNamara and Gonzales 2011; Taniguchi 2006) particularly of school age-in the household have been found to correlate with parents' volunteering. Parents are thought to be 'plugged into volunteering activities' through school and youth activities (McNamara and Gonzales 2011, p. 500). Domestic and family responsibilities are a barrier to women's volunteering more than men's (Einolf 2011; Fyall and Gazley 2015; Taniguchi 2006; Windebank 2008). However, changing family structures (i.e. away from the 'nuclear family') and gender roles with regard to employment may be adversely affecting the relationship between volunteering and marriage, particularly for women (Ogunye and Parker 2015) and for older people expected to take on greater caring roles (Fengyan et al. 2009). Tiehen (2000) also finds that where married women are having fewer children, they may be less exposed to volunteering opportunities.

\section{Employment}

Conditions around employment have been found to affect volunteering of men and women in different ways. Men may be more likely to volunteer when they are in (fulltime) employment (Fyall and Gazley 2015; Taniguchi 2006), whereas women who do not work or who work parttime have been found to be far more likely to volunteer both formally and informally (Helms and McKenzie 2014). Women may be less likely than male colleagues to receive employer support for volunteering (MacPhail and Bowles 2009). In the USA, increases in paid employment (Tiehen 2000) and additional family care responsibilities (Taniguchi 2006) may be a barrier to female volunteering.

\section{Social Exclusion}

The review has so far highlighted a range of barriers that may affect the capacity of different groups to volunteer. The final theme is how the unequal distribution of social, human, and economic capital resources profoundly affects volunteering. Studies conducting regression analyses of data from the USA (Lee and Brudney 2012; Wilson and Musick 1998), Canada (Smith 2012), Israel (Youssim et al. 2015), Italy (Marta and Pozzi 2008), and Spain (Mainar et al. 2015) all point to factors associated with broader exclusionary mechanisms-social, economic, and human capital-being significant influences on volunteering.

There is a growing body of evidence demonstrating a significant positive relationship between social capitalthe 'ability of actors to secure benefits by virtue of membership in social networks' (Portes 1998, p. 6)—and philanthropic behaviour, including volunteering (Forbes and Zampelli 2014; Layton and Moreno 2014; Zhuang and Girginov 2012). People or groups with low levels of social capital may be less likely to volunteer because they may have less contact with diverse people or organisations that provide opportunities for volunteering (Cramm and Nieboer 2015; Forbes and Zampelli 2014; Lee and Brudney 2012; Wilson and Musick 1998). The effects of social capital may be compounded by other factors such as education, being religious, and family background (Lee and Brudney 2012). A linked concept is 'cultural capital', with the ability to 'act' in a given social context in order to identify and avail volunteering opportunities transmitted from one generation to another within social groups (Youssim et al. 2015).

A positive relationship between individuals' level of education and skills_-human capital—and volunteering has been observed in the USA (Forbes and Zampelli 2014; Ishizawa 2014; Mesch et al. 2006; Wilson and Musick 1998), Canada (Smith 2012), mainland Europe (Plagnol and Huppert 2010), and Germany (Helms and McKenzie 2014). Higher human capital is thought to enable individuals to make better use of their social networks in order to identify and utilise opportunities for volunteering (Wilson and Musick 1998), whereas a lack of human capital may reduce individuals' ambition and expectations of their own participation in volunteering (Brodie et al. 2011).

Finally, economic capital has been linked to volunteering prevalence (Berliner 2013; Hussein and Manthorpe 2014; Plagnol and Huppert 2010; Taniguchi 2006; Wilson and Musick 1998). Higher income may allow more discretionary spending and afford people a greater stake in society (Wilson and Musick 1998). Those with higher incomes may also have a higher social network density, creating more opportunities to volunteer. Conversely, for 
those lacking in economic capital, volunteering might be a luxury they cannot-literally and figuratively-afford (Berliner 2013; Plagnol and Huppert 2010; Taniguchi 2006).

\section{Discussion}

Volunteering encompasses a broad range of activities that help or benefit those beyond one's immediate family or environment undertaken without the need for remuneration (Lee and Brudney 2012, p. 159). A commonly held defining feature of volunteering is that activities are freely chosen. However, the findings of this review suggest that these choices may be significantly constrained by structural level inequalities and aspects of the socio-cultural context.

Using the Equality Act 2010 'protected characteristics' was a useful initial framework to explore factors affecting volunteering for different demographic groups. The review has highlighted the plethora of 'levels' of barriers to volunteering at different life stages (i.e. personal, familial, social, institutional, structural). Findings show differences between groups and some demographic descriptors, such as age, disability, and gender, appear to be associated with a broader range of barriers to volunteering. This may, however, be reflective of a dearth of evidence in other areas. It is surprising that no literature concerning barriers to volunteering and 'sexual orientation' was identified in this review given the strong traditions of citizen activism and volunteer/peer health programmes in lesbian, gay, bisexual, and transgender (LGBT) communities (Gates et al. 2016). It may be that these activities are not called 'volunteering' within these communities. The variation in evidence about potentially disadvantaged groups merits further exploration using systematic review methods, with more sophisticated search strategies to locate literature.

This review contributes to a growing body of evidence identifying broader exclusionary mechanisms relating to social, economic, and human capital as a crosscutting concern to participation in volunteering (Lee and Brudney 2012; Mainar et al. 2015; Marta and Pozzi 2008; Smith 2012; Wilson and Musick 1998; Youssim et al. 2015). This is not to diminish the unique experience of individuals or groups. Rather, our analysis suggests that whilst different demographic groups encounter specific barriers to volunteering, these exist within a framework of structural factors related to broader, crosscutting exclusionary processes and social inequalities (see Table 5). This reflects Wilson and Music's (1997) finding that social statuses like age, race, and gender have only a largely indirect effect on volunteerism. Moreover, the interactions between demography and factors affecting volunteer participation are not simple, but compounded. For example, whilst women may have additional caring responsibilities and receive less employer support to volunteer compared to men, this experience is likely to be different depending on other attributes, including but not limited to age, socio-economic status, religion, or disability.

Volunteering is an activity that can bring health and well-being benefits to those involved and more broadly to communities and society (Public Health England 2015). However, volunteering has a social gradient, with people from more disadvantaged areas less likely to volunteer (Department for Communities and Local Government 2011; NNVIA - The Network of National Volunteer-Involving Agencies 2011). This means that those groups of people who may stand to gain the most from volunteering are least likely to take part. The variations in prevalence and therefore the unequal distribution of health and wellbeing benefits from volunteering suggest that this may be a health inequalities issue. The potential public health implications of volunteering mean there is much to be gained from broadening participation, particularly in the pathways and connections that can be made for disadvantaged groups. That there are significant barriers that stop people from volunteering has been recognised by government (Office of the Third Sector 2005). However, the dominant policy discourse around volunteering adopts an uncritical view of participation: that it is a matter of individual choice and that people are able to participate with ease. This is at odds with evidence from this review and elsewhere that participation in volunteering is socially determined by inequalities in access, opportunity, and resources. Particularly troublesome is the attachment of volunteer work to formal organisations, which means that communities or countries where the infrastructure of nongovernmental organisations outside the private sector is poorly developed will have fewer opportunities (Wilson 2012). Stakeholders should not focus solely on micro- or macro-barriers as our argument is that barriers occur at all 'levels' and that these levels are interconnected.

Given the relationship between wider exclusionary factors and volunteering, pathways to participation need to be developed in conjunction with addressing broader equity issues. Jenkinson et al. (2013), reporting on a systematic review of the health and survival of volunteers, point out that the positive health effects of volunteering may in fact be due to selection bias and reverse causation and that the focus needs to be on widening participation for socially disadvantaged groups. So that people can experience the virtuous circle of volunteering when they choose to and gain maximum benefits in terms of their health and well-being, consideration needs to be given to how to foster greater human, economic, and social capital across society. Volunteering can be related to community membership (e.g. religion, ethnicity, social interest), and so greater 
cohesion within and between groups should be fostered to facilitate greater involvement.

Encouraging volunteering requires a life course approach to deal with different barriers and facilitators, starting with support for young people to become involved in volunteering through to ensuring those in old age can continue to contribute if they wish. More could be done to remove the stigma preventing people from volunteering and to highlight the diversity of volunteering, along with ensuring a range of opportunities are available. Provision to facilitate the involvement of people from different demographic groups in volunteering, including young people, those with disabilities and those from ethnic minorities, needs to be more personalised to the needs of respective groups. The review findings suggest that there is scope to improve the volunteer experience. This requires a systematic approach to addressing barriers and providing inclusive volunteer opportunities to ensure that people can choose to volunteer in ways where the most benefit can be had, and within diverse organisations and communities.

\section{Limitations and Future Research}

This review is not a comprehensive account of the barriers to volunteering, rather an overview of some pertinent issues and themes. Limited time and resource meant restrictions had to be placed on the breadth and depth of searching. There is a need for a comprehensive systematic review of the available evidence concerning barriers and facilitators to volunteering and their effects on and pathways to reducing social and health inequalities.

The review has drawn on evidence from a global perspective, as the intention was to provide a broad overview of the barriers to volunteering. The evidence in this review comes mostly from high-income countries, specifically the USA and UK, and so may not be relevant to medium- or low-income countries. This is not entirely surprising given documented publication bias towards the USA in the literature more generally (Yeung 2001). It is not clear the extent to which international studies can be synthesised when issues around volunteering are often dependent on social and cultural context, although there do appear to be shared issues. Further primary research and secondary data analysis of the barriers to volunteering in demographic groups on a country-by-country basis would be beneficial to confirm these findings.

Although a significant body of literature exists concerning volunteering and inequalities, there are gaps in our understanding of the barriers that particular demographic groups may experience. No research was identified exploring either pregnancy and/or maternity/paternity or sexual orientation and barriers to volunteering. The majority of the identified literature in relation to ethnicity or religion and volunteering was from a non-UK context. The literature concerning relationship status and volunteering exclusively focused on heterosexual marriage. Further primary research and secondary data analysis of volunteering patterns in relation to sexual orientation and disability would be beneficial in bridging current gaps in knowledge.

\section{Conclusion}

This paper is an attempt to understand the breadth and interconnectedness of factors affecting volunteering for different demographic groups. It has produced a map of individual and structural factors affecting volunteering for those with characteristics protected under the UK Equality Act 2010. Whilst different demographic groups experience distinct barriers to volunteering, crosscutting issues relating to broader exclusionary processes affect all 'disadvantaged' groups. This shifts the onus of volunteering away from the level of individual choice (a dominant factor emphasized in policy and practical discussions around promoting volunteering) and towards the influence of broader patterns of social exclusion and economic inequality as major determinants of volunteerism ability.

There is a body of knowledge on the health and wellbeing benefits of volunteering. The results of this review illuminate some major inequalities in access to, and participation in, volunteering that are related to socio-economic (dis)advantage. Whilst pro-social activity, including volunteering, is increasingly encouraged as a solution to health problems, particularly for those at risk of social isolation or poor mental health, there are questions about the success of this approach given that underlying social inequities present substantive barriers to volunteering, and must be addressed to promote greater access.

Acknowledgements The authors would like to thank Mandy James (Volunteering Matters) for her support throughout the review process. Further thanks goes to steering group members Duncan Tree (Volunteering Matters), Dave Buck (The King's Fund), and Andrew Tyson (independent health consultant) for their support.

\section{Compliance with Ethical Standards}

Conflict of interest The authors declare that they have no conflict of interest.

Open Access This article is distributed under the terms of the Creative Commons Attribution 4.0 International License (http://crea tivecommons.org/licenses/by/4.0/), which permits unrestricted use, distribution, and reproduction in any medium, provided you give appropriate credit to the original author(s) and the source, provide a link to the Creative Commons license, and indicate if changes were made. 


\section{References}

Alspach, J. G. (2014). Harnessing the therapeutic power of volunteering, editorial. Critical Care Nurse, 34(6), 11-14.

Balandin, S., Llewellyn, G., Dew, A., Ballin, L., \& Schneider, J. (2006). Older disabled workers' perceptions of volunteering. Disability \& Society, 21(7), 677-692.

Bang, H. (2015). Volunteer age, job satisfaction, and intention to stay. Leadership \& Organization Development Journal, 36(2), 161.

Berliner, D. C. (2013). Inequality, poverty, and the socialization of america's youth for the responsibilities of citizenship. Theory Into Practice, 52(3), 203-209. https://doi.org/10.1080/00405841. 2013.804314.

Birdwell, J., \& Littler, M. (2012). "Why those who do God, do good...": Faithful Citizens. London: Demos.

Bortree, D. S., \& Waters, R. D. (2014). Race and inclusion in volunteerism: Using communication theory to improve volunteer retention. Journal of Public Relations Research, 26(3), 215-234. https://doi.org/10.1080/1062726X.2013.864245.

Brodie, E., Hughes, T., Jochum, V., Miller, S., Ockenden, N., \& Warburton, D. (2011). Pathways through participation: What creates and sustains active citizenship?. London: NCVO.

Bryant, W., Jeon-Slaughter, H., Kang, H., \& Tax, A. (2003). Participation in philanthropic activities: Donating money and time. Journal of Consumer Policy, 26, 42-73.

Cabinet Office. (2016). Community life survey 2014 to 2015: Data. https://www.gov.uk/government/publications/community-lifesurvey-2014-to-2015-data. Accessed Feb 2016.

Cattan, M., Hogg, E., \& Hardill, I. (2011). Review: Improving quality of life in ageing populations: What can volunteering do? Maturitas, 70, 328-332. https://doi.org/10.1016/j.maturitas. 2011.08.010.

Connolly, S., \& O'shea, E. (2015). The perceived benefits of participating in voluntary activities among older people: Do they differ by volunteer characteristics? Activities, Adaptation \& Aging, 39(2), 95-108. https://doi.org/10.1080/01924788.2015. 1024075.

Cramm, J. M., \& Nieboer, A. P. (2015). Background characteristics, resources and volunteering among older adults (aged $\geq 70$ years) in the community: A longitudinal study. Geriatrics \& Gerontology International, 15(8), 1087-1095. https://doi.org/10. 1111/ggi.12404.

Davis Smith, J. (1999). Poor marketing or the decline of altruism? Young people and volunteering in the United Kingdom. International Journal of Nonprofit \& Voluntary Sector Marketing, 4(4), 372.

Department for Communities and Local Government. (2011). Community action in England: A report on the 2009-10 citizenship survey. London: Cabinet Office.

Department of Health. (2011). Social action for health and wellbeing: Building co-operative communities. Leeds: Department of Health Strategic Vision for Volunteering.

Einolf, C. J. (2011). Gender differences in the correlates of volunteering and charitable giving. Nonprofit \& Voluntary Sector Quarterly, 40(6), 1092-1112. https://doi.org/10.1177/ 0899764010385949.

England, N. H. S. (2014). NHS five year forward view. London: NHS England.

Farrell, C., \& Bryant, W. (2009). Voluntary work for adults with mental health problems: A route to inclusion? A review of the literature. British Journal of Occupational Therapy (College of Occupational Therapists Limited), 72(4), 163-173.

Fegan, C., \& Cook, S. (2012). Experiences of volunteering: A partnership between service users and a mental health service in the UK. Work (Reading, Mass.), 43(1), 13-21. https://doi.org/10. 3233/wor-2012-1443.

Fegan, C., \& Cook, S. (2014). The therapeutic power of volunteering. Advances in Psychiatric Treatment, 20(3), 217-224. https://doi. org/10.1192/apt.bp.113.011890.

Fengyan, T., Morrow-Howell, N., \& Songiee, H. (2009). Inclusion of diverse older populations in volunteering. Nonprofit \& Voluntary Sector Quarterly, 38(5), 810.

Forbes, K. F., \& Zampelli, E. M. (2014). Volunteerism: The influences of social, religious, and human capital. Nonprofit \& Voluntary Sector Quarterly, 43(2), 227-253. https://doi.org/10. $1177 / 0899764012458542$.

Fyall, R., \& Gazley, B. (2015). Applying social role theory to gender and volunteering in professional associations. VOLUNTAS: International Journal of Voluntary and Nonprofit Organizations, 26(1), 288-314. https://doi.org/10.1007/s11266-013-9430-1.

Gates, T. G., Russell, E. B., \& Gainsburg, J. (2016). Volunteers work for lesbian, gay, bisexual, transgender, and queer rights: Motivations at a Rochester social justice organization. Journal of Gay \& Lesbian Social Services, 28(1), 39.

Gilbert, H., Buck, D., \& South, J. (2018). Volunteering in general practice: Opportunities and insights. London: The King's Fund.

Greenhalgh, T., Thorne, S., \& Malterud, K. (2018). Time to challenge the spurious hierarchy of systematic over narrative reviews? European Journal of Clinical Investigation. https://doi.org/10. 1111/eci.12931.

Harden, A., Sheridan, K., McKeown, A., Dan-Ogosi, I., \& Bagnall, A. M. (2015). Evidence review of barriers to, and facilitators of, community engagement approaches and practices in the UK. London: Insititute for Health and Human Development, University of East London.

Harris, J., Springett, J., Croot, L., Booth, A., Campbell, F., Thompson, G., et al. (2015). Can community-based peer support promote health literacy and reduce inequalities?. A realist review: Retrieved from.

Helms, S., \& McKenzie, T. (2014). Gender differences in formal and informal volunteering in Germany. VOLUNTAS: International Journal of Voluntary and Nonprofit Organizations, 25(4), 887-904. https://doi.org/10.1007/s11266-013-9378-1.

Hupert, F., Marks, N., Clark, A., Siegrist, J., Stutzer, A., Vitters $\varnothing$, J., et al. (2009). Measuring well-being across Europe: Description of the ESS well-being module and preliminary findings. Social Indicators Research. https://doi.org/10.1007/s11205-008-9346-

Hussein, S., \& Manthorpe, J. (2014). Volunteers Supporting older people in formal care settings in England: Personal and local factors influencing prevalence and type of participation. Journal of Applied Gerontology, 33(8), 923.

Ishizawa, H. (2014). Volunteerism among Mexican youth in the United States: The role of family capital. Hispanic Journal of Behavioral Sciences, 36(3), 247.

Ishizawa, H. (2015). Civic participation through volunteerism among youth across immigrant generations. Sociological Perspectives, 58(2), 264-285.

Jenkinson, C. E., Dickens, A. P., Jones, K., Thompson-Coon, J., Rtaylor, R. S., Trogers, M., et al. (2013). Is volunteering a public health intervention? A systematic review and meta-analysis of the health and survival of volunteers. BMC Public Health, 13, 773.

Johnston, J. B. (2013). Religion and volunteering over the adult life course. The Journal for the Scientific Study of Religion, 52(4), 733. https://doi.org/10.1111/jssr.12065/abstract.

Kay, T., \& Bradbury, S. (2009). Youth sport volunteering: Developing social capital? Sport, Education \& Society, 14(1), 121-140. https://doi.org/10.1080/13573320802615288. 
Khangura, S., Konnyu, K., Cushman, R., Grimshaw, J., \& Moher, D. (2012). Evidence summaries: The evolution of a rapid review approach. Systematic Reviews, 1(1), 10. https://doi.org/10.1186/ 2046-4053-1-10.

Kim, E. S., \& Konrath, S. H. (2016). Volunteering is prospectively associated with health care use among older adults. Social Science and Medicine, 149, 122-129. https://doi.org/10.1016/j. socscimed.2015.11.043.

Kolnick, L., \& Mulder, J. (2007). Strategies to improve recruitment of male volunteers in nonprofit agencies. American Journal of Hospice \& Palliative Medicine, 24(2), 98-104.

Layton, M. D., \& Moreno, A. (2014). Philanthropy and social capital in Mexico. International Journal of Nonprofit \& Voluntary Sector Marketing, 19(3), 209-219. https://doi.org/10.1002/nvsm. 1498.

Lee, Y.-J., \& Brudney, J. L. (2012). Participation in formal and informal volunteering: Implications for volunteer recruitment. Nonprofit Management \& Leadership, 23(2), 159.

Lum, T. Y., \& Lightfoot, E. (2005). The effects of volunteering on the physical and mental health of older people. Research on Aging, 27(1), 31-55.

MacPhail, F., \& Bowles, P. (2009). Corporate social responsibility as support for employee volunteers: Impacts, gender puzzles and policy implications in Canada. Journal of Business Ethics, 84(3), 405 .

Mainar, I., Servós, C., \& Gil, M. (2015). Analysis of volunteering among Spanish children and young people: Approximation to their determinants and parental influence. VOLUNTAS: International Journal of Voluntary and Nonprofit Organizations, 26(4), 1360-1390. https://doi.org/10.1007/s11266-014-9487-5.

Marta, E., \& Pozzi, M. (2008). Young people and volunteerism: A model of sustained volunteerism during the transition to adulthood. Journal of Adult Development, 15(1), 35-46.

McNamara, T. K., \& Gonzales, E. (2011). Volunteer transitions among older adults: The role of human, social, and cultural capital in later life. Journals of Gerontology. Series B, Psychological Sciences and Social Sciences, 66B(4), 490-501. https:// doi.org/10.1093/geronb/gbr055.

Mesch, D., Rooney, P., Steinberg, K., \& Denton, B. (2006). The effects of race, gender, and marital status on giving and volunteering in Indiana. Nonprofit \& Voluntary Sector Quarterly, 35(4), 565-587.

Musick, M., \& Wilson, J. (2007). Volunteers: A social profile. Bloomington, IN: Indiana University Press.

Musick, M. A., Wilson, J., \& Bynum, W. B. (2000). Race and formal volunteering: The differential effects of class and religion. Social Forces, 78(4), 1539-1570.

Naylor, C., Mundle, C., Weaks, L., \& Buck, D. (2013). Volunteering in health and social care. Securing a sustainable future. London: The Kings Fund.

Nicol, S. (2012). Volunteering and young people. Youth Studies Australia, 31(3), 3.

NNVIA - The Network of National Volunteer-Involving Agencies. (2011). Overcoming barriers to volunteering. London: NNVIA.

O'Brien, L., Buris, A., Townsend, M., \& Ebden, M. (2010). Volunteering in nature as a way of enabling people to reintegrate into society. Perspectives in Public Health. https://doi.org/10. $1177 / 1757913910384048$

Ockenden, N. (2007). Volunteering in the natural outdoors in the UK and Ireland: A literature review. London: Institute for Volunteering Research.

O’Donnell, G. C., Deaton, A., Durand, M., Halpern, D., \& Layard, R. (2014). Wellbeing and policy. London: Legatum Institute.

Office of the Third Sector. (2005). Volunteering: Compact code of good practise. London: Cabinet Office.
Ogunye, T., \& Parker, I. (2015). Giving back going forwards: How volunteering should respond to changing needs. London: Citizens Advice.

Pantea, M. C. (2013). Young people in cross-national volunteering: Perceptions of unfairness. Journal of Social and Personal Relationships, 30(5), 564-581.

Pathak, P., \& McGhee, D. (2015). 'I thought this was a Christian thing?' Exploring virtuous and exclusionary cycles in faith-based social action. Community Development Journal, 50(1), 40.

People and Communities Board. (2016). Six principles for engaging people and communities. Putting them into practice. London: People and Communities Board with support from National Voices.

Plagnol, A. C., \& Huppert, F. A. (2010). Happy to help? Exploring the factors associated with variations in rates of volunteering across Europe. Social Indicators Research, 97, 157.

Popay, J. (Ed.). (2006). Moving beyond effectiveness in evidence synthesis: Methodological issues in the synthesis of diverse sources of evidence. London: National Institute for Health and Clinical Excellence.

Portes, A. (1998). Social capital: Its origins and applications in modern sociology. Annual Review of Sociology, 24(1), 1-24.

Public Health England. (2015). A guide to community-centred approaches for health and wellbeing. London: Publich Health England.

Roker, D., Player, K., \& Coleman, J. (1998). Challenging the image: The involvement of young people with disabilities in volunteering and campaigning. Disability \& Society, 13(5), 725-741.

Rotolo, T., \& Wilson, J. (2014). Social heterogeneity and volunteering in U.S. cities. Sociological Forum, 29(2), 429-452. https:// doi.org/10.1111/socf.12091.

Salt, E., Crofford, L. J., \& Segerstrom, S. (2017). Original article: The mediating and moderating effect of volunteering on pain and depression, life purpose, well-being, and physical activity. Pain Management Nursing, 18, 243-249. https://doi.org/10.1016/j. pmn.2017.04.004.

Smith, A. (2012). The changing effects of community characteristics on volunteering in Canada. Canadian Public Policy, 38(3), 361-373.

Son, J., \& Wilson, J. (2012). Using normative theory to explain the effect of religion and education on volunteering. Sociological Perspectives, 53(3), 473.

South, J., White, J., \& Gamsu, M. (2013). People-centred public health. Bristol: The Policy Press.

Southby, K., \& South, J. (2016a). Volunteering, inequalities \& public health: Barriers to volunteering-Summary report. London: Volunteering Matters.

Southby, K., \& South, J. (2016b). Volunteering, inequalities and barriers to volunteering: A rapid evidence review. Leeds: Leeds Beckett University.

Storm, I. (2015). Religion, inclusive individualism, and volunteering in Europe. Journal of Contemporary Religion, 30(2), 213-229. https://doi.org/10.1080/13537903.2015.1025542.

Suanet, B., Broese van Groenou, M., \& Braam, A. W. (2009). Changes in volunteering among young old in the Netherlands between 1992 and 2002: The impact of religion, age-norms, and intergenerational transmission. European Journal of Ageing, 6(3), 157-165. https://doi.org/10.1007/s10433-009-0119-7.

Taniguchi, H. (2006). Men's and women's volunteering: Gender differences in the effects of employment and family characteristics. Nonprofit \& Voluntary Sector Quarterly, 35(1), 83-101.

The National Archives. (2016). Department for communities and local government: 2009-10 citizenship survey: Community action 2009-10 tables [Online]. The National Archives. Available: http://webarchive.nationalarchives.gov.uk/20120919132719/ 
http://www.communities.gov.uk/publications/corporate/statis tics/citizenshipsurvey200910action. Accessed Oct 2016.

Thomas, J., Newman, M., \& Oliver, S. (2013). Rapid evidence assessments of research to inform social policy: Taking stock and moving forward. Evidence \& Policy: A Journal of Research, Debate and Practice, 9(1), 5-27. https://doi.org/10.1332/ $174426413 \times 662572$.

Tiehen, L. (2000). Has working more caused married women to volunteer less? Evidence from time diary data, 1965 to 1993. Nonprofit \& Voluntary Sector Quarterly, 29(4), 505-529.

Trembath, D., Balandin, S., Stancliffe, R. J., \& Togher, L. (2010). Employment and volunteering for adults with intellectual disability. Journal of Policy \& Practice in Intellectual Disabilities, 7(4), 235-238. https://doi.org/10.1111/j.1741-1130.2010. 00271.x.

van Goethem, A. A. J., van Hoof, A., van Aken, M. A. G., Orobio de Castro, B., \& Raaijmakers, Q. A. W. (2014). Socialising adolescent volunteering: How important are parents and friends? Age dependent effects of parents and friends on adolescents' volunteering behaviours. Journal of Applied Developmental Psychology, 35, 94-101. https://doi.org/10.1016/j.appdev.2013. 12.003.

Varker, T., Forbes, D., Dell, L., Weston, A., Merlin, T., Hodson, S., et al. (2015). Rapid evidence assessment: Increasing the transparency of an emerging methodology. Journal of Evaluation in Clinical Practice, 21(6), 1199-1204. https://doi.org/10. 1111/jep.12405.

Warburton, J., \& Winterton, R. (2010). The role of volunteering in an era of cultural transition: Can it provide a role identity for older people from asian cultures? Diversity (14242818), 2(8), 1048-1058. https://doi.org/10.3390/d2081048.

Webber, R. (2011). Volunteering among Australian adolescents: Findings from a national study. Youth Studies Australia, 30(1), 9-16.
Wilson, J. (2012). Volunteerism: A review essay. Nonprofit and Voluntary Sector Quarterly, 41(2), 176-212.

Wilson, J., \& Janoski, T. (1995). The contribution of religion to volunteer work. Sociology of Religion, 56(2), 137-152.

Wilson, J., \& Musick, M. (1997). Who cares? Toward an integrated theory of volunteer work. American Sociological Review, 62(5), 694-713.

Wilson, J., \& Musick, M. (1998). The contribution of social resources to volunteering. Social Science Quarterly (University of Texas Press), 79(4), 799-814.

Windebank, J. E. (2008). Volunteering and the gender division of labour: A Franco-British comparison. Community, Work \& Family, 11(4), 457-473. https://doi.org/10.1080/ 13668800802349802.

Yeung, H. (2001). Redressing the geographical bias in social science knowledge. London, England: SAGE Publications Sage UK.

Yeung, J. W. K., Zhuoni, Z., \& Tae Yeun, K. (2017). Volunteering and health benefits in general adults: Cumulative effects and forms. BMC Public Health, 17, 1.

Young, J., \& Passmore, A. (2007). What is the occupational therapy role in enabling mental health consumer participation in volunteer work? Australian Occupational Therapy Journal, 54(1), 66-69.

Youssim, I., Hank, K., \& Litwin, H. (2015). The role of family social background and inheritance in later life volunteering: Evidence from SHARE-Israel. Research on Aging, 37(1), 3.

Zhuang, J., \& Girginov, V. (2012). Volunteer selection and social, human and political capital: A case study of the Beijing 2008 Olympic games. Managing Leisure, 17(2/3), 239-256.

Publisher's Note Springer Nature remains neutral with regard to jurisdictional claims in published maps and institutional affiliations. 